\title{
Synthesis and antitubercular evaluation of 2-iminothiazolidine-4-ones
}

\author{
Ganesh Samala, Chunduri Madhuri, Jonnalagadda Padma Sridevi, \\ Radhika Nallangi, Yogeeswari Perumal, and Sriram Dharmarajan * \\ Antitubercular Drug Discovery Laboratory, Department of Pharmacy, Birla Institute of Technology and Science, Pilani, Hyderabad Campus, Jawahar Nagar, \\ Hyderabad, 500078, India \\ *Corresponding author at: Antitubercular Drug Discovery Laboratory, Department of Pharmacy, Birla Institute of Technology and Science, Pilani, Hyderabad \\ Campus, Jawahar Nagar, Hyderabad, 500078, India. \\ Tel.:+91.40.66303506. Fax:+91.40.66303998. E-mail address: dsriram@hyderabad.bits-pilani.ac.in (S. Dharmarajan).
}

\section{COMMUNICATION INFORMATION}

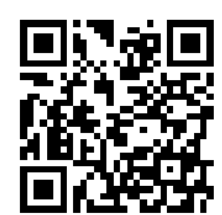

DOI: $10.5155 /$ eurjchem.5.3.550-556.1059

Received: 25 March 2014

Received in revised form: 29 April 2014

Accepted: 30 April 2014

Online: 30 September 2014

\section{KEYWORDS}

\section{Cytotoxicity}

Antitubercular activity

Thiazolidine derivatives

Mycobacterium tuberculosis

Structure activity relationship

Minimum inhibitory concentration

\section{Introduction}

Despite the existence of treatments for tuberculosis (TB), nine million people are currently infected and one and a half million die, each year [1]. The disease also represents an escalating threat for global health, with the increasing prevalence of multi drug resistant (MDR) and extensively drug resistant (XDR) TB strains [2]. Despite this, the development of new drugs with novel modes of action for the treatment of TB would likely still be the most cost-effective way of tackling the pandemic. Specifically, any new drug should be able to shorten the duration of treatment, avoid significant drug-drug interacttion with current regimens, to treat MDR as well as XDR-TB patients $[3,4]$.

Target-based approaches are widely used in drug discovery; questions have been raised about the efficiency of this approach given the very high attrition rates that these projects have historically shown in the anti-infective field $[5,6]$. Furthermore, the state of affairs is a symptom of wider inconsistencies between results obtained with animal models of infection and their translation to clinical therapeutic value in humans. Compounds identified in whole-cell screens fulfil a double function: (i) they provide lead structures for further optimization within the drug development progression sequence, and (ii) they can be exploited as tools to identify new targets. Notably, cell-based hits already fulfil some important criteria, including permeability issues and, given the progression criteria in the high-throughput screen, higher activity against mycobacteria than mammalian cells. Thus, they provide suitable chemical and biological starting points.

The Tuberculosis Antimicrobial Acquisition and Coordinating Facility (TAACF) was established by the National Institute of Allergy and Infectious Diseases (NIAID) in 1994 to allow researchers access to high quality screening services in order to encourage antituberculosis drug discovery research. Recently TAACF reported their anti-TB high-throughput results of large libraries of drug like small molecules [7-9], among them one of the molecule SID: 24823007 5-(furan-2-yl methylene)-2-imino-3-(thiazol-2-yl)thiazolidin-4-one) showed good activity against Mycobacterium tuberculosis H37Rv with minimum inhibitory concentration of $<0.2 \mu \mathrm{M}$ and selectivity index of $>115$ (Figure 1).

We have taken SID: 24823007 as the starting point to design more analogues by keeping 2-imino thiazolidine-4-one nucleus intact and modify $3^{\text {rd }}$ and $5^{\text {th }}$ position with various aryl and heteroaryl moiety to study the structure activity relationship (SAR) of the lead compound. 


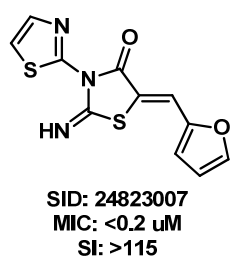

Figure 1. Antitubercular lead compound.

\section{Experimental}

\subsection{Instrumentation}

All the reagents obtained from commercial sources were used without further purification. All reactions were run under inert atmosphere of nitrogen or argon. All the reactions were monitored by thin layer chromatography (TLC) on silica gel 40 $\mathrm{F}_{254}$ (Merck, Darmstadt, Germany) coated on aluminium plates. ${ }^{1} \mathrm{H}$ and ${ }^{13} \mathrm{C}$ NMR spectra were recorded on a Bruker AM-300 or 400 NMR spectrometer, Bruker BioSpin Corp., Germany. Chemical shifts are in parts per million (ppm). In the Nuclear Magnetic resonance spectra ( ${ }^{1} \mathrm{H}$ NMR and ${ }^{13} \mathrm{C}$ NMR), the signals of the respective protons of the prepared 2-iminothiazolidine4-one derivatives were verified on the basis of their chemical shifts, multiplicities, and coupling constants. Temperatures are reported in degrees Celsius and are uncorrected. Compounds were analysed for $\mathrm{C}, \mathrm{H}, \mathrm{N}$ and analytical results obtained were within $\pm 0.4 \%$ of the calculated values for the formula shown. Molecular weights of the synthesised compounds were checked by (Shimadzu, LC/MS-2020) ESI-MS method.

\subsection{General procedure for synthesis of $N$-substituted chloroacetamides $(2 a-c)$}

Compound 1 (1.0 equiv.) and chloroacetyl chloride (1.0 equiv.) were taken in benzene and the reaction mixture was refluxed for $6 \mathrm{~h}$. after completion of the reaction monitored by TLC, the reaction mixture was diluted with EtOAc and washed with sat $\mathrm{NaHCO}_{3}, \mathrm{H}_{2} \mathrm{O}$ and Brine. The combined organic layer was dried over anhy $\mathrm{Na}_{2} \mathrm{SO}_{4}$, evaporated to get compound 2 .

2-Chloro- $N$-(3-(trifluoromethyl)phenyl)acetamide (2a): 3(Trifluoromethyl)aniline (3.0 g, $18.63 \mathrm{mmol}$ ) and chloroacetyl chloride (1.48 mL, $18.63 \mathrm{mmol})$ were taken in benzene $(25 \mathrm{~mL})$ and the reaction mixture was refluxed for $6 \mathrm{~h}$. The reaction mixture was diluted with EtOAc and washed with sat. $\mathrm{NaHCO}_{3}$ $(3 \times 30 \mathrm{~mL}), \mathrm{H}_{2} \mathrm{O}(2 \times 30 \mathrm{~mL})$ and Brine $(2 \times 20 \mathrm{~mL})$. The combined organic layer was dried over anhydrous $\mathrm{Na}_{2} \mathrm{SO}_{4}$, evaporated under vacuum to get solid product, the solids were washed with hexanes to get 2-chloro- $N$-(3-(trifluoromethyl) phenyl)acetamide. Color: Off-white solid. Yield: $3.60 \mathrm{~g}, 81 \% .{ }^{1} \mathrm{H}$ NMR (400 MHz, $\left.\mathrm{CDCl}_{3}, \delta, \mathrm{ppm}\right): 8.21(\mathrm{~s}, 1 \mathrm{H}, \mathrm{Ar}-\mathrm{H}), 7.77(\mathrm{~s}, 1 \mathrm{H}$, $\mathrm{NH}), 7.54(\mathrm{~d}, J=8.4 \mathrm{~Hz}, 1 \mathrm{H}, \mathrm{Ar}-\mathrm{H}), 7.49$ (d, J= $7.6 \mathrm{~Hz}, 1 \mathrm{H}, \mathrm{Ar}-\mathrm{H})$, $7.36(\mathrm{t}, J=7.6 \mathrm{~Hz}, 1 \mathrm{H}, \mathrm{Ar}-\mathrm{H}), 4.23\left(\mathrm{~s}, 2 \mathrm{H}, \mathrm{CH}_{2}\right)$.

MS (EI, $m / z(\%)): 238[\mathrm{M}+\mathrm{H}]^{+}$.

2-Chloro-N-(5-nitrothiazol-2-yl)acetamide (2b): 5-Nitro thiazol-2-amine ( $3.0 \mathrm{~g}, 20.80 \mathrm{mmol})$ and chloroacetyl chloride $(1.64 \mathrm{~mL}, 20.80 \mathrm{mmol})$ were taken in benzene $(25 \mathrm{~mL})$ and the reaction mixture was refluxed for $6 \mathrm{~h}$. The reaction mixture was diluted with EtOAc and washed with sat. $\mathrm{NaHCO}_{3}(3 \times 30 \mathrm{~mL})$, $\mathrm{H}_{2} \mathrm{O}(2 \times 30 \mathrm{~mL})$ and Brine $(2 \times 20 \mathrm{~mL})$. The combined organic layer was dried over anhydrous $\mathrm{Na}_{2} \mathrm{SO}_{4}$, evaporated under vacuum to get solid product, the solids were washed with hexanes to get 2-chloro- $N$-(5-nitrothiazol-2-yl)acetamide. Color: Off-white solid. Yield: $3.40 \mathrm{~g}, 74 \%$. ${ }^{1} \mathrm{H}$ NMR $(400 \mathrm{MHz}$, DMSO- $\left.d_{6}, \delta, \mathrm{ppm}\right): 9.43$ (s, $\left.1 \mathrm{H}, \mathrm{NH}\right), 8.64(\mathrm{~s}, 1 \mathrm{H}, \mathrm{Ar}-\mathrm{H}), 4.24$ (s, $2 \mathrm{H}, \mathrm{CH}_{2}$ ). MS (EI, $\left.m / z(\%)\right): 222[\mathrm{M}+\mathrm{H}]^{+}$.

2-Chloro-N-(6-nitrobenzo[d] thiazol-2-yl)acetamide (2c): 6Nitrobenzo[d]thiazol-2-amine (3.0 g, $15.38 \mathrm{mmol})$ and chloroacetyl chloride $(1.21 \mathrm{~mL}, 15.38 \mathrm{mmol})$ were taken in benzene $(25 \mathrm{~mL})$ and the reaction mixture was refluxed for $6 \mathrm{~h}$. The reaction mixture was diluted with EtOAc and washed with sat. $\mathrm{NaHCO}_{3}(3 \times 30 \mathrm{~mL}), \mathrm{H}_{2} \mathrm{O}(2 \times 30 \mathrm{~mL})$ and Brine $(2 \times 20$ $\mathrm{mL}$ ). The combined organic layer was dried over anhydrous $\mathrm{Na}_{2} \mathrm{SO}_{4}$, evaporated under vacuum to get solid product, the solids were washed with hexanes to get 2-chloro- $N$-(6-nitro benzo[d]thiazol-2-yl)acetamide. Color: Off-white solid. Yield: $2.97 \mathrm{~g}, 71 \%$. ${ }^{1 \mathrm{H}} \mathrm{NMR}\left(400 \mathrm{MHz}, \mathrm{DMSO}-d_{6}, \delta, \mathrm{ppm}\right): 10.03$ (s, $1 \mathrm{H}$, $\mathrm{NH}), 8.49(\mathrm{~s}, 1 \mathrm{H}, \mathrm{Ar}-\mathrm{H}), 8.32$ (d, $J=8.4 \mathrm{~Hz}, 1 \mathrm{H}, \mathrm{Ar}-\mathrm{H}), 8.22(\mathrm{~d}, J=$ $8.0 \mathrm{~Hz}, 1 \mathrm{H}, \mathrm{Ar}-\mathrm{H}$ ), 4.26 (s, $2 \mathrm{H}, \mathrm{CH}_{2}$ ). MS (EI, $m / z(\%)$ ): 272 $[\mathrm{M}+\mathrm{H}]^{+}$.

\subsection{General procedure for synthesis of 3-substituted-2- iminothiazolidine-4-one (3a-c)}

Compound 2a-c (1.0 equiv) and KSCN (1.6 equiv) were taken in dry acetone and refluxed for $2 \mathrm{~h}$. The reaction mixture was concentrated and obtained solid was washed with $\mathrm{H}_{2} \mathrm{O}$ and dried in vacuum oven to get compound 3a-c.

2-Imino-3-(3-(trifluoromethyl)phenyl)thiazolidin-4-one (3a): 2-Chloro- $N$-(3-(trifluoromethyl)phenyl)acetamide $(3.60 \mathrm{~g}$, 15.18 mmoles) and KSCN (2.36 g, 24.30 mmoles) were taken in dry acetone and refluxed for $2 \mathrm{~h}$. The reaction mixture was concentrated and obtained solid was washed with $\mathrm{H}_{2} \mathrm{O}$ and dried in vacuum oven to get compound 2-imino-3-(3(trifluoromethyl)phenyl)thiazolidin-4-one. Yield: $3.30 \mathrm{~g}, 83 \%$. Color: Off-white solid. ${ }^{1} \mathrm{H}$ NMR $\left(400 \mathrm{MHz}, \mathrm{CDCl}_{3}, \delta, \mathrm{ppm}\right): 9.12$ (s, 1H, NH), $7.78(\mathrm{~s}, 1 \mathrm{H}, \mathrm{Ar}-\mathrm{H}), 7.64$ (d, J = 8.0 Hz, 1H, Ar-H), 7.54 $(\mathrm{d}, J=7.6 \mathrm{~Hz}, 1 \mathrm{H}, \mathrm{Ar}-\mathrm{H}), 7.45(\mathrm{t}, J=7.6 \mathrm{~Hz}, 1 \mathrm{H}, \mathrm{Ar}-\mathrm{H}), 4.32(\mathrm{~s}$, $2 \mathrm{H}, \mathrm{CH}_{2}$ ). MS (EI, $\left.m / z(\%)\right): 261[\mathrm{M}+\mathrm{H}]^{+}$.

2-Imino-3-(5-nitrothiazol-2-yl)thiazolidin-4-one (3b): 2Chloro- $N$-(5-nitrothiazol-2-yl)acetamide $\quad(3.40 \mathrm{~g}, \quad 15.38$ mmoles) and KSCN (2.40 g, 24.61 mmoles) were taken in dry acetone and refluxed for $2 \mathrm{~h}$. The reaction mixture was concentrated and obtained solid was washed with $\mathrm{H}_{2} \mathrm{O}$ and dried in vacuum oven to get compound 2-imino-3-(5nitrothiazol-2-yl)thiazolidin-4-one. Yield: 3.15 g, 84\%. Color: Off-white solid. ${ }^{1} \mathrm{H}$ NMR (400 MHz, DMSO- $\left.d_{6}, \delta, \mathrm{ppm}\right): 9.97$ (s, $1 \mathrm{H}, \mathrm{NH}), 8.81(\mathrm{~s}, 1 \mathrm{H}, \mathrm{Ar}-\mathrm{H}), 4.27\left(\mathrm{~s}, 2 \mathrm{H}, \mathrm{CH}_{2}\right)$.

MS (EI, $m / z(\%)): 245[\mathrm{M}+\mathrm{H}]^{+}$.

2-Imino-3-(6-nitrobenzo[d]thiazol-2-yl)thiazolidin-4-one (3c): 2-Chloro- $N$-(6-nitrobenzo[d] thiazol-2-yl)acetamide (2.97 g, 10.95 mmoles) and KSCN (1.71 g, 17.53 mmoles) were taken in dry acetone and refluxed for $2 \mathrm{~h}$. The reaction mixture was concentrated and obtained solid was washed with $\mathrm{H}_{2} \mathrm{O}$ and dried in vacuum oven to get compound 2-imino-3-(6nitrobenzo[d]thiazol-2-yl)thiazolidin-4-one. Yield: $2.34 \mathrm{~g}, 72 \%$. Color: Off-white solid. ${ }^{1} \mathrm{H}$ NMR (400 MHz, DMSO- $\left.d_{6}, \delta, \mathrm{ppm}\right)$ : $9.72(\mathrm{~s}, 1 \mathrm{H}, \mathrm{NH}), 8.53(\mathrm{~s}, 1 \mathrm{H}, \mathrm{Ar}-\mathrm{H}), 8.34(\mathrm{~d}, J=8.4 \mathrm{~Hz}, 1 \mathrm{H}, \mathrm{Ar}-\mathrm{H})$, $8.17(\mathrm{~d}, J=8.0 \mathrm{~Hz}, 1 \mathrm{H}, \mathrm{Ar}-\mathrm{H}), 4.20\left(\mathrm{~s}, 2 \mathrm{H}, \mathrm{CH}_{2}\right)$. MS (EI, $m / z$ (\%)): $295[\mathrm{M}+\mathrm{H}]^{+}$.

\subsection{General procedure for synthesis of compounds $4 a-1,5 a-1$ and $6 a-1$}

2-Imino-3-(3-(trifluoromethyl)phenyl)thiazolidin-4-one (3a) (0.25 g, $0.96 \mathrm{mmol}), \mathrm{NaOAc}(0.15 \mathrm{~g}, 1.92$ mmoles $)$ and 2hydroxybenzaldehyde $(0.14 \mathrm{~g}, 1.15 \mathrm{mmol})$ were taken in acetic acid $(2.0 \mathrm{~mL})$ and heated at $100{ }^{\circ} \mathrm{C}$ for 3 hours, the solids formed in the reaction mixture were filtered and washed with water, little amount of ethanol and hexanes to afford title compound $(0.38 \mathrm{~g}, 90 \%)$ as an off-white solid (4a).

5-(2-Hydroxybenzylidene)-2-imino-3-(3-(trifluoromethyl) phenyl)thiazolidin-4-one (4a): Color: Brown. Yield: $90 \% .{ }^{1} \mathrm{H}$ NMR (400 MHz, DMSO-d $6, \delta, p p m): 11.51(\mathrm{~s}, 1 \mathrm{H}, \mathrm{OH}), 10.02(\mathrm{~s}$, $1 \mathrm{H}, \mathrm{NH}), 8.30$ (s, 1H, Ar-H), 7.81 (d, $J=8.0 \mathrm{~Hz}, 1 \mathrm{H}, \mathrm{Ar}-\mathrm{H}), 7.78-$ $7.60(\mathrm{~m}, 4 \mathrm{H}, \mathrm{Ar}-\mathrm{H}+\mathrm{CH}), 7.54-7.36(\mathrm{~m}, 3 \mathrm{H}, \mathrm{Ar}-\mathrm{H}) .{ }^{13} \mathrm{C}$ NMR $(100$ MHz, DMSO- $\left.d_{6}, \delta, \mathrm{ppm}\right): 169.0,153.4,152.3,144.9,136.5,133.2$, $131.5,128.4,127.3,127.0,126.4,125.7,124.4,123.6,122.4$, 121.3, 119.4. MS (EI, $m / z(\%)): 365[\mathrm{M}+\mathrm{H}]^{+}$. Anal. calcd. for 
$\mathrm{C}_{17} \mathrm{H}_{11} \mathrm{~F}_{3} \mathrm{~N}_{2} \mathrm{O}_{2} \mathrm{~S}: \mathrm{C}, 56.04 ; \mathrm{H}, 3.04 ; \mathrm{N}, 7.69$. Found: $\mathrm{C}, 56.12 ; \mathrm{H}$, $3.10 ; \mathrm{N}, 7.72 \%$.

5-(4-Hydroxybenzylidene)-2-imino-3-(3-(trifluoromethyl) phenyl)thiazolidin-4-one (4b): Color: White. Yield: $88 \% .{ }^{1} \mathrm{H}$ NMR (400 MHz, DMSO- $\left.d_{6}, \delta, p p m\right): 12.91(\mathrm{~s}, 1 \mathrm{H}, \mathrm{OH}), 9.42(\mathrm{~s}$, $1 \mathrm{H}, \mathrm{NH}), 8.34$ (s, 1H, Ar-H), 7.99 (d, $J=7.6 \mathrm{~Hz}, 2 \mathrm{H}, \mathrm{Ar}-\mathrm{H}), 7.72-$ $7.63(\mathrm{~m}, 4 \mathrm{H}, \mathrm{Ar}-\mathrm{H}+\mathrm{CH}), 7.27(\mathrm{~d}, J=8.0 \mathrm{~Hz}, 2 \mathrm{H}, \mathrm{Ar}-\mathrm{H}) .{ }^{13} \mathrm{C}$ NMR (100 MHz, DMSO- $\left.d_{6}, \delta, \mathrm{ppm}\right): 166.8,160.6,152.4,149.4,134.5$, $133.4,130.5$ (2C), 129.8, 129.1, 127.4, 126.3, 125.4, 124.7, 123.4 (2C), 119.7. MS (EI, $m / z(\%)): 365[\mathrm{M}+\mathrm{H}]^{+}$. Anal. calcd. for $\mathrm{C}_{17} \mathrm{H}_{11} \mathrm{~F}_{3} \mathrm{~N}_{2} \mathrm{O}_{2} \mathrm{~S}$ : C, 56.04; $\mathrm{H}, 3.04 ; \mathrm{N}, 7.69$. Found: C, 56.14; $\mathrm{H}$, $3.10 ; \mathrm{N}, 7.77 \%$.

2-Imino-5-(4-methoxybenzylidene)-3-(3-(trifluoromethyl) phenyl)thiazolidin-4-one (4c): Color: Brown. Yield: 79\%. ${ }^{1} \mathrm{H}$ NMR $(300 \mathrm{MHz}, \delta, \mathrm{ppm}): 12.40(\mathrm{~s}, 1 \mathrm{H}, \mathrm{NH}), 8.78-7.20(\mathrm{~m}, 3 \mathrm{H}$, Ar-H), 7.92-7.77 (m, 4H, Ar-H + CH), 7.69-7.54 (m, 2H, Ar-H), $4.05\left(\mathrm{~s}, 3 \mathrm{H}, \mathrm{CH}_{3}\right) .{ }^{13} \mathrm{C}$ NMR $\left(75 \mathrm{MHz}, \mathrm{DMSO}-d_{6}, \delta, \mathrm{ppm}\right): 163.5$, $156.4,149.4,144.5,136.4,135.3,133.4$ (2C), 132.6, 130.5, 129.5, 127.6, 126.0, 125.4, 124.6, 123.3 (2C), 120.6. MS (EI, $m / z$ (\%)): $379[\mathrm{M}+\mathrm{H}]^{+}$. Anal calcd for $\mathrm{C}_{18} \mathrm{H}_{13} \mathrm{~F}_{3} \mathrm{~N}_{2} \mathrm{O}_{2} \mathrm{~S}: \mathrm{C}, 57.14 ; \mathrm{H}$, 3.46; N, 7.40. Found: C, 57.21; H, 3.48; N, 7.43\%.

5-(4-(Benzyloxy)benzylidene)-2-imino-3-(3-(trifluoromethyl) phenyl)thiazolidin-4-one (4d): Color: Brown. Yield: 93\%. ${ }^{1} \mathrm{H}$ NMR $\left(300 \mathrm{MHz}, \mathrm{CDCl}_{3}, \delta, \mathrm{ppm}\right): 12.45$ (s, $\left.1 \mathrm{H}, \mathrm{NH}\right), 8.56$ (s, $1 \mathrm{H}$, $\mathrm{Ar}-\mathrm{H}), 8.12(\mathrm{~d}, J=7.6 \mathrm{~Hz}, 2 \mathrm{H}, \mathrm{Ar}-\mathrm{H}), 7.99-7.72(\mathrm{~m}, 6 \mathrm{H}, \mathrm{Ar}-\mathrm{H}+$ $\mathrm{CH}), 7.63-7.51(\mathrm{~m}, 5 \mathrm{H}, \mathrm{Ar}-\mathrm{H}), 4.99\left(\mathrm{~s}, 2 \mathrm{H}, \mathrm{CH}_{2}\right) .{ }^{13} \mathrm{C}$ NMR $(75$ $\mathrm{MHz}, \mathrm{CDCl}_{3}, \delta$, ppm): 167.3, 161.1, 154.3, 148.7, 139.5, 138.4, $137.4,136.3(2 \mathrm{C}), 134.5,133.2(2 \mathrm{C}), 131.4,130.4(2 \mathrm{C}), 129.6$, $128.4,127.4,126.3(2 \mathrm{C}), 125.2,123.4,120.5,69.3$. MS (EI, $m / z$ (\%)): $455[\mathrm{M}+\mathrm{H}]^{+}$. Anal calcd for $\mathrm{C}_{24} \mathrm{H}_{17} \mathrm{~F}_{3} \mathrm{~N}_{2} \mathrm{O}_{2} \mathrm{~S}: \mathrm{C}, 63.43 ; \mathrm{H}$, 3.77; N, 6.16. Found: C, 63.52; H, 3.87; N, 6.25\%.

2-Imino-5-(4-methylbenzylidene)-3-(3-(trifluoromethyl) phenyl)thiazolidin-4-one (4e): Color: White. Yield: $81 \% .{ }^{1} \mathrm{H}$ NMR $\left(300 \mathrm{MHz}, \mathrm{DMSO}-d_{6}, \delta, \mathrm{ppm}\right): 12.24(\mathrm{~s}, 1 \mathrm{H}, \mathrm{NH}), 8.34(\mathrm{~s}, 1 \mathrm{H}, \mathrm{Ar}-$ $\mathrm{H}), 7.89(\mathrm{~d}, J=7.6 \mathrm{~Hz}, 2 \mathrm{H}, \mathrm{Ar}-\mathrm{H}), 7.81-7.72(\mathrm{~m}, 6 \mathrm{H}, \mathrm{Ar}-\mathrm{H}+\mathrm{CH})$, $2.52\left(\mathrm{~s}, 3 \mathrm{H}, \mathrm{CH}_{3}\right) .{ }^{13} \mathrm{C}$ NMR $\left(75 \mathrm{MHz}, \mathrm{CDCl}_{3}, \delta, \mathrm{ppm}\right): 164.3$, $159.4,155.3,152.4,141.3,139.5,138.4,136.4,135.4$ (2C), 133.2, 130.4 (2C), 127.4, 126.4, 125.3, 122.4, 22.5. MS (EI, $m / z$ (\%)): $363[\mathrm{M}+\mathrm{H}]^{+}$. Anal calcd for $\mathrm{C}_{18} \mathrm{H}_{13} \mathrm{~F}_{3} \mathrm{~N}_{2} \mathrm{OS}$ : C, 59.66; $\mathrm{H}$, 3.62; N, 7.73. Found: C, 59.73; H, 3.67; N, 7.87\%.

5-(4-(Dimethylamino)benzylidene)-2-imino-3-(3-(trifluoro methyl)phenyl)thiazolidin-4-one (4f): Color: Brown. Yield: 84\%. ${ }^{1} \mathrm{H}$ NMR (400 MHz, $\left.\mathrm{CDCl}_{3}, \delta, \mathrm{ppm}\right): 9.99(\mathrm{~s}, 1 \mathrm{H}, \mathrm{NH}), 8.28(\mathrm{~s}, 1 \mathrm{H}$, Ar-H), 7.97 (d, J = 7.6 Hz, 2H, Ar-H), 7.82-7.74 (m, 2H, Ar-H + $\mathrm{CH}), 7.63-7.45(\mathrm{~m}, 4 \mathrm{H}, \mathrm{Ar}-\mathrm{H}), 3.15\left(\mathrm{~s}, 6 \mathrm{H}, 2 \mathrm{CH}_{3}\right) .{ }^{13} \mathrm{C}$ NMR $(100$ $\left.\mathrm{MHz}, \mathrm{CDCl}_{3}, \delta, \mathrm{ppm}\right): 164.4,154.4,152.6,143.4,136.4,134.5$, 133.6 (2C), 132.9, 132.1, 131.3 (2C), 127.5, 126.4, 124.6, 123.4, 120.4, 43.2 (2C). MS (EI, $m / z(\%)): 392[\mathrm{M}+\mathrm{H}]^{+}$. Anal calcd for $\mathrm{C}_{19} \mathrm{H}_{16} \mathrm{~F}_{3} \mathrm{~N}_{3} \mathrm{OS}$ : C, 58.30; H, 4.12; N, 10.74. Found: $\mathrm{C}, 58.41 ; \mathrm{H}$, $4.18 ; \mathrm{N}, 10.83 \%$.

2-Imino-3-(3-(trifluoromethyl)phenyl)-5-(3,4,5-trimethoxy benzylidene)thiazolidin-4-one (4g): Color: White. Yield: $89 \% .{ }^{1} \mathrm{H}$ NMR $\left(400 \mathrm{MHz}, \mathrm{CDCl}_{3}, \delta, \mathrm{ppm}\right): 12.60(\mathrm{~s}, 1 \mathrm{H}, \mathrm{NH}), 8.49(\mathrm{~s}, 1 \mathrm{H}$, Ar-H), 8.10-8.01 (m, 2H, Ar-H), 7.99 (s, 1H, CH), 7.63 (d, J = 7.2 $\mathrm{Hz}, 1 \mathrm{H}, \mathrm{Ar}-\mathrm{H}), 7.49(\mathrm{~s}, 2 \mathrm{H}, \mathrm{Ar}-\mathrm{H}), 4.12\left(\mathrm{~s}, 9 \mathrm{H}, 3 \mathrm{CH}_{3}\right) .{ }^{13} \mathrm{C}$ NMR (100 MHz, $\left.\mathrm{CDCl}_{3}, \delta, \mathrm{ppm}\right): 168.3,162.4(2 \mathrm{C}), 161.1,152.4,149.6$, $142.3,138.5,137.4,135.9,133.0,131.4,128.4,126.2,124.2$, 123.4 (2C), 63.4, 61.2 (2C). MS (EI, $m / z(\%)): 439[\mathrm{M}+\mathrm{H}]^{+}$. Anal. calcd. for $\mathrm{C}_{20} \mathrm{H}_{17} \mathrm{~F}_{3} \mathrm{~N}_{2} \mathrm{O}_{4} \mathrm{~S}$ : C, $54.79 ; \mathrm{H}, 3.91 ; \mathrm{N}, 6.39$. Found: C, 54.82; H, 3.98; N, 6.36\%.

5-(2-Fluorobenzylidene)-2-imino-3-(3-(trifluoromethyl) phenyl)thiazolidin-4-one (4h): Color: Light Yellow. Yield: $80 \%$. ${ }^{1} \mathrm{H}$ NMR $(400 \mathrm{MHz}$, DMSO-d6, $\delta, \mathrm{ppm}): 12.42(\mathrm{~s}, 1 \mathrm{H}, \mathrm{NH}), 7.99$ (s, $1 \mathrm{H}, \mathrm{Ar}-\mathrm{H}), 7.92(\mathrm{~s}, 1 \mathrm{H}, \mathrm{CH}), 7.81-7.74(\mathrm{~m}, 2 \mathrm{H}, \mathrm{Ar}-\mathrm{H}), 7.63(\mathrm{~d}, J=$ $6.8 \mathrm{~Hz}, 1 \mathrm{H}, \mathrm{Ar}-\mathrm{H}), 7.58-7.49$ (m, 4H, Ar-H). ${ }^{13} \mathrm{C}$ NMR $(100 \mathrm{MHz}$, DMSO- $\left.d_{6}, \delta, \mathrm{ppm}\right): 167.2,162.2,154.3,149.6,135.3,134.6$, $133.2,129.2,126.3,126.0,125.2,123.7,123.2,122.6,121.4$, 120.3, 119.9. MS (EI, $m / z(\%)$ ):367 [M+H]+. Anal. calcd. for $\mathrm{C}_{17} \mathrm{H}_{10} \mathrm{~F}_{4} \mathrm{~N}_{2} \mathrm{OS}$ : C, 55.74; H, 2.75; N, 7.65. Found: C, 55.81; H, $2.81 ; \mathrm{N}, 7.74 \%$.
5-(4-Chlorobenzylidene)-2-imino-3-(3-(trifluoromethyl) phenyl)thiazolidin-4-one (4i): Color: Light Yellow. Yield: 79\%. ${ }^{1} \mathrm{H}$ NMR $\left(400 \mathrm{MHz}, \mathrm{DMSO}-d_{6}, \delta, \mathrm{ppm}\right): 12.88(\mathrm{~s}, 1 \mathrm{H}, \mathrm{NH}), 8.21(\mathrm{~s}$, $1 \mathrm{H}, \mathrm{Ar}-\mathrm{H}), 7.81$ (d, $J=7.2 \mathrm{~Hz}, 2 \mathrm{H}, \mathrm{Ar}-\mathrm{H}), 7.77$ (d, $J=6.8 \mathrm{~Hz}, 1 \mathrm{H}$, Ar-H), 7.72-7.68 (m, 3H, Ar-H + CH), 7.35 (d, $J=8.0 \mathrm{~Hz}, 2 \mathrm{H}, \mathrm{Ar}-$ H). ${ }^{13} \mathrm{C}$ NMR (100 MHz, DMSO- $d_{6}, \delta$, ppm): 167.2, 163.3, 155.2, $148.9,136.8,136.2,135.3(2 \mathrm{C}), 133.8,130.4,129.4,127.2$, 126.4, 124.7(2C), 123.1, 120.6. MS (EI, $m / z(\%)): 383[\mathrm{M}+\mathrm{H}]^{+}$. Anal. calcd. for $\mathrm{C}_{17} \mathrm{H}_{10} \mathrm{ClF}_{3} \mathrm{~N}_{2} \mathrm{OS}$ : C, 53.34; $\mathrm{H}, 2.63 ; \mathrm{N}, 7.32$. Found: C, 53.37; H, 2.72; N, 7.41\%.

2-Imino-5-(3-nitrobenzylidene)-3-(3-(trifluoromethyl) phenyl)thiazolidin-4-one (4j): Color: Yellow. Yield: $76 \% .{ }^{1} \mathrm{H}$ NMR (400 MHz, DMSO- $\left.d_{6}\right)$ : $12.94(\mathrm{~s}, 1 \mathrm{H}, \mathrm{NH}), 8.34(\mathrm{~s}, 1 \mathrm{H}, \mathrm{Ar}-\mathrm{H})$ $8.21(\mathrm{~s}, 1 \mathrm{H}, \mathrm{Ar}-\mathrm{H}), 7.98$ (d, $J=7.6 \mathrm{~Hz}, 1 \mathrm{H}, \mathrm{Ar}-\mathrm{H}), 7.81-7.74(\mathrm{~m}$ $3 \mathrm{H}, \mathrm{Ar}-\mathrm{H}+\mathrm{CH}), 7.63-7.54(\mathrm{~m}, 3 \mathrm{H}, \mathrm{Ar}-\mathrm{H}) .{ }^{13} \mathrm{C}$ NMR $(100 \mathrm{MHz}$, DMSO- $\left.d_{6}, \delta, \mathrm{ppm}\right): 164.6,162.2,151.2,146.4,137.8,136.3$, $134.2,133.8,132.6,131.6,130.4,128.2,126.7,125.1,124.2$ 123.2, 121.5. MS (EI, $m / z(\%)): 394[\mathrm{M}+\mathrm{H}]^{+}$. Anal. calcd. for $\mathrm{C}_{17} \mathrm{H}_{10} \mathrm{~F}_{3} \mathrm{~N}_{3} \mathrm{O}_{3} \mathrm{~S}: \mathrm{C}, 51.91 ; \mathrm{H}, 2.56 ; \mathrm{N}, 10.68$. Found: $\mathrm{C}, 51.94 ; \mathrm{H}$, $2.62 ; \mathrm{N}, 10.73 \%$.

2-Imino-5-((5-nitrofuran-2-yl)methylene)-3-(3-(trifluoro methyl)phenyl)thiazolidin-4-one (4k): Color: Yellow. Yield: 92\%. ${ }^{1} \mathrm{H}$ NMR $\left(400 \mathrm{MHz}, \mathrm{CDCl}_{3}, \delta, \mathrm{ppm}\right): 12.63(\mathrm{~s}, 1 \mathrm{H}, \mathrm{NH}), 8.31$ (d, $J=$ $7.2 \mathrm{~Hz}, 1 \mathrm{H}, \mathrm{Ar}-\mathrm{H}$ ), 8.21 (s, 1H, Ar-H), 7.92 (d, J= 7.2 Hz, 1H, Ar$\mathrm{H}), 7.81-7.72(\mathrm{~m}, 2 \mathrm{H}, \mathrm{Ar}-\mathrm{H}+\mathrm{CH}), 7.58(\mathrm{~d}, J=7.2 \mathrm{~Hz}, 1 \mathrm{H}, \mathrm{Ar}-\mathrm{H})$ $7.54(\mathrm{t}, J=7.2 \mathrm{~Hz}, 1 \mathrm{H}, \mathrm{Ar}-\mathrm{H}) .{ }^{13} \mathrm{C}$ NMR $\left(100 \mathrm{MHz}, \mathrm{CDCl}_{3}, \delta, \mathrm{ppm}\right)$ : $168.1,160.2,153.2,152.1,149.3,136.3,135.3,134.9,133.9$, 131.4, 127.2, 126.4, 124.2, 122.1, 120.5. MS (EI, $m / z$ (\%)): 384 $[\mathrm{M}+\mathrm{H}]^{+}$. Anal. calcd. for $\mathrm{C}_{15} \mathrm{H}_{8} \mathrm{~F}_{3} \mathrm{~N}_{3} \mathrm{O}_{4} \mathrm{~S}: \mathrm{C}, 47.00 ; \mathrm{H}, 2.10 ; \mathrm{N}$, 10.96. Found: C, 47.11; H, 2.13; N, 10.98\%.

2-Imino-5-((5-nitrothiophen-2-yl)methylene)-3-(3-(trifluoro methyl)phenyl)thiazolidin-4-one (41): Color: Light Yellow. Yield: $72 \% .{ }^{1} \mathrm{H}$ NMR ( $\left.400 \mathrm{MHz}, \mathrm{CDCl}_{3}, \delta, \mathrm{ppm}\right): 12.51(\mathrm{~s}, 1 \mathrm{H}, \mathrm{NH}), 8.29$ (d, $J=7.2 \mathrm{~Hz}, 1 \mathrm{H}, \mathrm{Ar}-\mathrm{H}), 8.19$ (s, 1H, Ar-H), 7.89 (d, $J=7.2 \mathrm{~Hz}$, $1 \mathrm{H}, \mathrm{Ar}-\mathrm{H}), 7.79-7.69(\mathrm{~m}, 2 \mathrm{H}, \mathrm{Ar}-\mathrm{H}+\mathrm{CH}), 7.63(\mathrm{~d}, J=7.2 \mathrm{~Hz}, 1 \mathrm{H}$, Ar-H), $7.58(\mathrm{t}, J=7.2 \mathrm{~Hz}, 1 \mathrm{H}, \mathrm{Ar}-\mathrm{H}) .{ }^{13} \mathrm{C}$ NMR $\left(100 \mathrm{MHz}, \mathrm{CDCl}_{3}, \delta\right.$, ppm): 166.9, 161.1, 152.3, 150.3, 148.2, 135.5, 134.1, 133.4 $132.9,130.2,128.4,126.2,122.3,120.3,118.8$. MS (EI, $m / z$ (\%)): $400[\mathrm{M}+\mathrm{H}]^{+}$. Anal. calcd. for $\mathrm{C}_{15} \mathrm{H}_{8} \mathrm{~F}_{3} \mathrm{~N}_{3} \mathrm{O}_{3} \mathrm{~S}_{2}$ : C, 45.11; $\mathrm{H}$, 2.02; N, 10.52. Found: C, 45.19; H, 2.10; N, 10.59\%.

5-(2-Hydroxybenzylidene)-2-imino-3-(5-nitrothiazol-2-yl) thiazolidin-4-one (5a): Color: White. Yield: $88 \% .{ }^{1} \mathrm{H}$ NMR $(400$ MHz, DMSO- $\left.d_{6}, \delta, \mathrm{ppm}\right): 12.42(\mathrm{~s}, 1 \mathrm{H}, \mathrm{OH}), 9.70(\mathrm{~s}, 1 \mathrm{H}, \mathrm{NH}), 8.31$ (s, $1 \mathrm{H}, \mathrm{Ar}-\mathrm{H}), 7.92(\mathrm{~d}, J=7.2 \mathrm{~Hz}, 1 \mathrm{H}, \mathrm{Ar}-\mathrm{H}), 7.81(\mathrm{~s}, 1 \mathrm{H}, \mathrm{CH})$ 7.72-7.69 (m, 2H, Ar-H), $7.63(\mathrm{t}, J=7.6 \mathrm{~Hz}, 1 \mathrm{H}, \mathrm{Ar}-\mathrm{H}) .{ }^{13} \mathrm{C}$ NMR (100 MHz, DMSO- $\left.d_{6}, \delta, \mathrm{ppm}\right): 172.6,163.4,156.4,149.4,137.4$, $131.4,128.5,126.4,125.2,123.8,121.4,120.4,119.3$. MS (EI, $m / z(\%)): 349[\mathrm{M}+\mathrm{H}]^{+}$. Anal. calcd. for $\mathrm{C}_{13} \mathrm{H}_{8} \mathrm{~N}_{4} \mathrm{O}_{4} \mathrm{~S}_{2}: \mathrm{C}, 44.82 ; \mathrm{H}$, 2.31; N, 16.08. Found: C, 44.92; H, 2.41; N, $16.12 \%$.

5-(4-Hydroxybenzylidene)-2-imino-3-(5-nitrothiazol-2-yl) thiazolidin-4-one (5b): Color: White. Yield: $79 \% .{ }^{1} \mathrm{H}$ NMR (400 MHz, DMSO- $\left.d_{6}, \delta, \mathrm{ppm}\right): 12.78(\mathrm{~s}, 1 \mathrm{H}, \mathrm{OH}), 9.21(\mathrm{~s}, 1 \mathrm{H}, \mathrm{NH}), 8.31$ (s, 1H, Ar-H), $7.92(\mathrm{~s}, 1 \mathrm{H}, \mathrm{CH}), 7.63(\mathrm{~d}, J=7.6 \mathrm{~Hz}, 2 \mathrm{H}, \mathrm{Ar}-\mathrm{H}), 7.32$ (d, $J=8.0 \mathrm{~Hz}, 2 \mathrm{H}, \mathrm{Ar}-\mathrm{H}) .{ }^{13} \mathrm{C}$ NMR (100 MHz, DMSO- $\left.d_{6}, \delta, \mathrm{ppm}\right)$ : $169.9,163.6,154.9,148.5,134.5,132.4,129.5$ (2C), 127.8, 124.9, 123.1 (2C), 121.5. MS (EI, $m / z(\%)): 349[\mathrm{M}+\mathrm{H}]^{+}$. Anal. calcd. for $\mathrm{C}_{13} \mathrm{H}_{8} \mathrm{~N}_{4} \mathrm{O}_{4} \mathrm{~S}_{2}$ : C, 44.82; $\mathrm{H}, 2.31 ; \mathrm{N}, 16.08$. Found: $\mathrm{C}$, 44.94; H, 2.34; N, 16.18\%.

2-Imino-5-(4-methoxybenzylidene)-3-(5-nitrothiazol-2-yl) thiazolidin-4-one (5c): Color: Light Yellow. Yield: 94\%. ${ }^{1} \mathrm{H}$ NMR $\left(300 \mathrm{MHz}, \mathrm{DMSO}-d_{6}, \delta, \mathrm{ppm}\right): 13.12(\mathrm{~s}, 1 \mathrm{H}, \mathrm{NH}), 8.31(\mathrm{~s}, 1 \mathrm{H}, \mathrm{Ar}-$ H), $7.69(\mathrm{~s}, 1 \mathrm{H}, \mathrm{CH}), 7.65$ (d, J = 7.5 Hz, 2H, Ar-H), 7.29 (d, J = 7.2 $\mathrm{Hz}, 2 \mathrm{H}, \mathrm{Ar}-\mathrm{H}$ ), 3.99 (s, 3H, CH3). ${ }^{13} \mathrm{C}$ NMR (75 MHz, DMSO- $d_{6}, \delta$, ppm): 171.9, 166.6, 156.2, 150.5, 141.5, 136.2, 132.5 (2C), $128.3,126.3,122.4$ (2C), 120.6, 60.3. MS (EI, $m / z(\%)): 363$ $[\mathrm{M}+\mathrm{H}]^{+}$. Anal. calcd. for $\mathrm{C}_{14} \mathrm{H}_{10} \mathrm{~N}_{4} \mathrm{O}_{4} \mathrm{~S}_{2}: \mathrm{C}, 46.40 ; \mathrm{H}, 2.78 ; \mathrm{N}, 15.46$. Found: C, 46.51; H, 2.81; N, 15.52\%.

5-(4-(Benzyloxy)benzylidene)-2-imino-3-(5-nitrothiazol-2-yl) thiazolidin-4-one (5d): Color: Brown. Yield: $93 \% .{ }^{1} \mathrm{H}$ NMR $(300$ $\mathrm{MHz}, \mathrm{CDCl}_{3}, \delta, \mathrm{ppm}$ ): 13.12 (s, 1H, NH), 8.53 (s, 1H, Ar-H), 7.81 (s, 1H, CH), 7.72 (d, J = 7.2 Hz, 2H, Ar-H), 7.67-7.54 (m, 7H, Ar- 
$\mathrm{H}), 5.22\left(\mathrm{~s}, 2 \mathrm{H}, \mathrm{CH}_{2}\right) .{ }^{13} \mathrm{C} \mathrm{NMR}\left(75 \mathrm{MHz}, \mathrm{CDCl}_{3}, \delta, \mathrm{ppm}\right): 169.6$, $162.6,154.7,144.9,139.6,136.6,134.2,133.2$ (2C), 132.5, 132.0 (2C), 130.5, 128.2 (2C), 126.2, 124.8 (2C), 120.6, 70.2. MS (EI, $m / z(\%)$ ): $439[\mathrm{M}+\mathrm{H}]^{+}$. Anal. calcd. for $\mathrm{C}_{20} \mathrm{H}_{14} \mathrm{~N}_{4} \mathrm{O}_{4} \mathrm{~S}_{2}$ : C, 54.78; H, 3.22; N, 12.78. Found: C, 54.85; H, 3.26; N, $12.81 \%$.

2-Imino-5-(4-methylbenzylidene)-3-(5-nitrothiazol-2-yl) thiazolidin-4-one (5e): Color: Light Yellow. Yield: 89\%. ${ }^{1 \mathrm{H}} \mathrm{NMR}$ (400 MHz, DMSO- $\left.d_{6}, \delta, \mathrm{ppm}\right): 12.54(\mathrm{~s}, 1 \mathrm{H}, \mathrm{NH}), 8.41(\mathrm{~s}, 1 \mathrm{H}, \mathrm{Ar}-$ $\mathrm{H}), 7.71(\mathrm{~d}, J=7.2 \mathrm{~Hz}, 2 \mathrm{H}, \mathrm{Ar}-\mathrm{H}), 7.67(\mathrm{~s}, 1 \mathrm{H}, \mathrm{CH}), 7.58(\mathrm{~d}, J=7.2$ $\mathrm{Hz}, 2 \mathrm{H}, \mathrm{Ar}-\mathrm{H}), 2.49\left(\mathrm{~s}, 3 \mathrm{H}, \mathrm{CH}_{3}\right) .{ }^{13} \mathrm{C}$ NMR $\left(100 \mathrm{MHz}, \mathrm{CDCl}_{3}, \delta\right.$, ppm): 172.1, 166.4, 152.5, 149.4, 138.4, 136.3, 135.2 (2C), 134.2, 131.4 (2C), 126.2, 122.1, 22.3. MS (EI, $\mathrm{m} / \mathrm{z}(\%)$ ): 347 $[\mathrm{M}+\mathrm{H}]^{+}$. Anal. calcd. for $\mathrm{C}_{14} \mathrm{H}_{10} \mathrm{~N}_{4} \mathrm{O}_{3} \mathrm{~S}_{2}: \mathrm{C}, 48.54 ; \mathrm{H}, 2.91 ; \mathrm{N}, 16.17$. Found: C, 48.61; H, 2.93; N, 16.21\%.

5-(4-(Dimethylamino)benzylidene)-2-imino-3-(5-nitrothia zol-2-yl)thiazolidin-4-one (5f): Color: Yellow. Yield: $76 \% .{ }^{1} \mathrm{H}$ NMR (400 MHz, DMSO- $\left.d_{6}, \delta, \mathrm{ppm}\right): 12.87(\mathrm{~s}, 1 \mathrm{H}, \mathrm{NH}), 8.35$ (s, $1 \mathrm{H}, \mathrm{Ar}-\mathrm{H}), 7.72(\mathrm{~s}, 1 \mathrm{H}, \mathrm{CH}), 7.63(\mathrm{~d}, J=7.2 \mathrm{~Hz}, 2 \mathrm{H}, \mathrm{Ar}-\mathrm{H}), 7.54$ (d, $J=8.0 \mathrm{~Hz}, 2 \mathrm{H}, \mathrm{Ar}-\mathrm{H}), 3.15\left(\mathrm{~s}, 6 \mathrm{H}, 2 \mathrm{CH}_{3}\right) .{ }^{13} \mathrm{C}$ NMR $(100 \mathrm{MHz}$, DMSO- $\left.d_{6}, \delta, \mathrm{ppm}\right): 169.9,164.1,153.3,149.4,141.4,136.4$, 133.2 (2C), 130.9, 128.8, 126.3 (2C), 125.5, 44.4 (2C). MS (EI, $m / z(\%)): 376[\mathrm{M}+\mathrm{H}]^{+}$. Anal. calcd. for $\mathrm{C}_{15} \mathrm{H}_{13} \mathrm{~N}_{5} \mathrm{O}_{3} \mathrm{~S}_{2}$ : C, 47.99; H, 3.49; N, 18.65. Found: C, 47.97; H, 3.58; N, 18.71\%.

2-Imino-3-(5-nitrothiazol-2-yl)-5-(3,4,5-trimethoxybenzylide ne)thiazolidin-4-one (5g): Color: Yellow. Yield: $88 \%$. ${ }^{1} \mathrm{H}$ NMR (400 MHz, DMSO- $\left.d_{6}, \delta, \mathrm{ppm}\right): 13.23(\mathrm{~s}, 1 \mathrm{H}, \mathrm{NH}), 8.45(\mathrm{~s}, 1 \mathrm{H}, \mathrm{Ar}-$ $\mathrm{H}), 7.72(\mathrm{~s}, 1 \mathrm{H}, \mathrm{CH}), 7.11(\mathrm{~s}, 2 \mathrm{H}, \mathrm{Ar}-\mathrm{H}), 3.90\left(\mathrm{~s}, 9 \mathrm{H}, 3 \mathrm{CH}_{3}\right) .{ }^{13} \mathrm{C}$ NMR (100 MHz, DMSO-d6, $\delta, p p m): 171.7,166.2,152.1$ (2C), 148.2, 146.3, 142.3, 137.2, 135.9, 132.6, 130.3, 126.4 (2C), 61.3, 60.6 (2C). MS (EI, $m / z(\%)$ ): $423[\mathrm{M}+\mathrm{H}]^{+}$. Anal. calcd. for $\mathrm{C}_{16} \mathrm{H}_{14} \mathrm{~N}_{4} \mathrm{O}_{6} \mathrm{~S}_{2}$ : C, 45.49; $\mathrm{H}, 3.34 ; \mathrm{N}, 13.26$. Found: $\mathrm{C}, 45.52 ; \mathrm{H}$, $3.41 ; \mathrm{N}, 13.32 \%$.

5-(2-Fluorobenzylidene)-2-imino-3-(5-nitrothiazol-2-yl) thiazolidin-4-one (5h): Color: Light Yellow. Yield: 78\%. ${ }^{1} \mathrm{H}$ NMR $\left(400 \mathrm{MHz}, \mathrm{DMSO}-d_{6}, \delta, \mathrm{ppm}\right): 11.91(\mathrm{~s}, 1 \mathrm{H}, \mathrm{NH}), 8.31(\mathrm{~s}, 1 \mathrm{H}, \mathrm{Ar}-$ $\mathrm{H}), 8.18(\mathrm{~s}, 1 \mathrm{H}, \mathrm{CH}), 7.94(\mathrm{~d}, J=7.6 \mathrm{~Hz}, 1 \mathrm{H}, \mathrm{Ar}-\mathrm{H}), 7.81-7.63(\mathrm{~m}$, $3 \mathrm{H}, \mathrm{Ar}-\mathrm{H}) .{ }^{13} \mathrm{C}$ NMR (100 MHz, DMSO- $\left.d_{6}, \delta, \mathrm{ppm}\right): 168.3,163.5$, $156.1,146.2,134.8,134.2,133.5,132.9,128.4,126.9,124.4$, 120.3, 119.4. MS (EI, $m / z(\%)): 350[\mathrm{M}+\mathrm{H}]^{+}$. Anal. calcd. for $\mathrm{C}_{13} \mathrm{H}_{7} \mathrm{FN}_{4} \mathrm{O}_{3} \mathrm{~S}_{2}$ : C, 44.57; H, 2.01; N, 15.99. Found: C, 44.61; H, $1.98 ; \mathrm{N}, 16.01 \%$.

5-(4-Chlorobenzylidene)-2-imino-3-(5-nitrothiazol-2-yl) thiazolidin-4-one (5i): Color: Brown. Yield: 81\%. ${ }^{1} \mathrm{H}$ NMR $(400$ MHz, DMSO- $\left.d_{6}, \delta, \mathrm{ppm}\right): 13.02(\mathrm{~s}, 1 \mathrm{H}, \mathrm{NH}), 8.41(\mathrm{~s}, 1 \mathrm{H}, \mathrm{Ar}-\mathrm{H})$, $7.81(\mathrm{~s}, 1 \mathrm{H}, \mathrm{CH}), 7.72(\mathrm{~d}, J=8.0 \mathrm{~Hz}, 2 \mathrm{H}, \mathrm{Ar}-\mathrm{H}), 7.56(\mathrm{~d}, J=8.0 \mathrm{~Hz}$, $2 \mathrm{H}, \mathrm{Ar}-\mathrm{H}) .{ }^{13} \mathrm{C}$ NMR (100 MHz, DMSO- $\left.d_{6}, \delta, \mathrm{ppm}\right): 166.9,160.2$, 152.7, 146.8, 137.4, 134.8, 133.3(2C), 132.3, 128.4(2C), 126.2, 121.5. MS (EI, $m / z \quad(\%)): 367 \quad[\mathrm{M}+\mathrm{H}]^{+}$. Anal. calcd. for $\mathrm{C}_{13} \mathrm{H}_{7} \mathrm{ClN}_{4} \mathrm{O}_{3} \mathrm{~S}_{2}$ : C, 42.57; H, 1.92; N, 15.27. Found: C, 42.63; H, $1.99 ; \mathrm{N}, 15.32 \%$.

2-Imino-5-(3-nitrobenzylidene)-3-(5-nitrothiazol-2-yl) thiazolidin-4-one (5j): Color: Yellow. Yield: $88 \% .{ }^{1} \mathrm{H}$ NMR $(400$ MHz, DMSO- $\left.d_{6}, \delta, \mathrm{ppm}\right): \delta 13.11(\mathrm{~s}, 1 \mathrm{H}, \mathrm{NH}), 8.32(\mathrm{~s}, 1 \mathrm{H}, \mathrm{Ar}-\mathrm{H})$, $8.27(\mathrm{~s}, 1 \mathrm{H}, \mathrm{CH}), 7.94-7.76(\mathrm{~m}, 3 \mathrm{H}, \mathrm{Ar}-\mathrm{H}), 7.62(\mathrm{t}, J=7.6 \mathrm{~Hz}, 1 \mathrm{H}$, Ar-H). ${ }^{13} \mathrm{C}$ NMR (100 MHz, DMSO- $\left.d_{6}, \delta, \mathrm{ppm}\right): 170.1,163.2$, $152.2,147.3,138.1,136.2,135.0,133.3,132.4,127.3,125.9$, 123.3, 121.6. MS (EI, $m / z(\%)): 378[\mathrm{M}+\mathrm{H}]^{+}$. Anal. calcd. for $\mathrm{C}_{13} \mathrm{H}_{7} \mathrm{~N}_{5} \mathrm{O}_{5} \mathrm{~S}_{2}$ : C, 41.38; H, 1.87; N, 18.56. Found: C, 41.41; H, 1.96; N, $18.61 \%$.

2-Imino-5-((5-nitrofuran-2-yl)methylene)-3-(5-nitrothiazol2-yl)thiazolidin-4-one (5k): Color: Brown. Yield: 69\%. ${ }^{1} \mathrm{H}$ NMR ( $\left.400 \mathrm{MHz}, \mathrm{CDCl}_{3}, \delta, \mathrm{ppm}\right): 13.21(\mathrm{~s}, 1 \mathrm{H}, \mathrm{NH}), 8.49$ (s, $\left.1 \mathrm{H}, \mathrm{Ar}-\mathrm{H}\right)$, 8.39 (d, $J=6.8 \mathrm{~Hz}, 1 \mathrm{H}, \mathrm{Ar}-\mathrm{H}), 8.21(\mathrm{~d}, J=7.2 \mathrm{~Hz}, 1 \mathrm{H}, \mathrm{Ar}-\mathrm{H}), 7.99$ (s, $1 \mathrm{H}, \mathrm{CH}) .{ }^{13} \mathrm{C}$ NMR $\left(100 \mathrm{MHz}, \mathrm{CDCl}_{3}, \delta, \mathrm{ppm}\right): 172.1,163.3$, $152.8,150.8,143.2,142.4,136.3,133.9,126.8,124.2,123.6$. MS (EI, $\mathrm{m} / z(\%)): 368[\mathrm{M}+\mathrm{H}]^{+}$. Anal. calcd. for $\mathrm{C}_{11} \mathrm{H}_{5} \mathrm{~N}_{5} \mathrm{O}_{6} \mathrm{~S}_{2}: \mathrm{C}$, 35.97; H, 1.37; N, 19.07. Found: C, 36.02; H, 1.39; N, 19.19\%.

2-Imino-3-(5-nitrothiazol-2-yl)-5-((5-nitrothiophen-2-yl) methylene)thiazolidin-4-one (51): Color: Brown. Yield: 76\%. ${ }^{1 \mathrm{H}}$ NMR (400 MHz, $\left.\mathrm{CDCl}_{3}, \delta, \mathrm{ppm}\right): 13.14(\mathrm{~s}, 1 \mathrm{H}, \mathrm{NH}), 8.53$ (s, 1H, Ar-H), 8.34 (d, J = 6.8 Hz, 1H, Ar-H), 8.17 (d, J = 7.2 Hz, 1H, Ar-
H), 7.82 (s, $1 \mathrm{H}, \mathrm{CH}) .{ }^{13} \mathrm{C}$ NMR (100 MHz, $\left.\mathrm{CDCl}_{3}, \delta, \mathrm{ppm}\right): 169.4$, $161.3,151.4,150.3,142.8,141.3,135.2,132.7,125.9,123.9$, 122.4. MS (EI, $m / z \quad \%)$ ): $384[\mathrm{M}+\mathrm{H}]^{+}$. Anal calcd for $\mathrm{C}_{11} \mathrm{H}_{5} \mathrm{~N}_{5} \mathrm{O}_{5} \mathrm{~S}_{3}: \mathrm{C}, 34.46 ; \mathrm{H}, 1.31 ; \mathrm{N}, 18.27$. Found: $\mathrm{C}, 34.52 ; \mathrm{H}$, $1.32 ; \mathrm{N}, 18.29 \%$.

5-(2-Hydroxybenzylidene)-2-imino-3-(6-nitrobenzo[d] thiazol-2-yl)thiazolidin-4-one (6a): Color: Light Yellow. Yield: 83\%. ${ }^{1} \mathrm{H}$ NMR ( $\left.400 \mathrm{MHz}, \mathrm{CDCl}_{3}, \delta, \mathrm{ppm}\right): 12.60(\mathrm{~s}, 1 \mathrm{H}, \mathrm{OH}), 9.49$ $(\mathrm{s}, 1 \mathrm{H}, \mathrm{NH}), 8.31(\mathrm{~d}, J=7.2 \mathrm{~Hz}, 1 \mathrm{H}, \mathrm{Ar}-\mathrm{H}), 8.12(\mathrm{~s}, 1 \mathrm{H}, \mathrm{CH}), 8.01$ (d, $J=7.2 \mathrm{~Hz}, 1 \mathrm{H}, \mathrm{Ar}-\mathrm{H}$ ), 7.81-7.74 (m, 4H, Ar-H), 7.63 (d, $J=8.0$ $\mathrm{Hz}, 1 \mathrm{H}, \mathrm{Ar}-\mathrm{H}) .{ }^{13} \mathrm{C}$ NMR $\left(100 \mathrm{MHz}\right.$, DMSO- $\left.d_{6}, \delta, \mathrm{ppm}\right): 169.6$, 161.1, 155.3, 148.8, 138.0, 136.1, 132.2, 130.5, 128.1, 127.4, 126.3, 125.8, 125.0, 124.0, 122.1, 120.6, 120.0. MS (EI, $\mathrm{m} / \mathrm{z}$ (\%)): $399[\mathrm{M}+\mathrm{H}]^{+}$. Anal. calcd. for $\mathrm{C}_{17} \mathrm{H}_{10} \mathrm{~N}_{4} \mathrm{O}_{4} \mathrm{~S}_{2}$ : C, 51.25; $\mathrm{H}$, 2.53; N, 14.06. Found: C, 51.30; H, 2.65; N, 14.16\%.

5-(4-Hydroxybenzylidene)-2-imino-3-(6-nitrobenzo[d] thiazol-2-yl)thiazolidin-4-one (6b): Color: Light Yellow. Yield: 81\%. ${ }^{1 \mathrm{H}}$ NMR (400 MHz, DMSO- $\left.d_{6}, \delta, \mathrm{ppm}\right): 13.05$ (s, $\left.1 \mathrm{H}, \mathrm{OH}\right)$, $9.36(\mathrm{~s}, 1 \mathrm{H}, \mathrm{NH}), 8.21(\mathrm{~d}, J=7.2 \mathrm{~Hz}, 1 \mathrm{H}, \mathrm{Ar}-\mathrm{H}), 8.18(\mathrm{~s}, 1 \mathrm{H}, \mathrm{Ar}-\mathrm{H})$ 8.01 (d, J = 6.8 Hz, 1H, Ar-H), 7.92 (s, 1H, CH), 7.77 (d, J= 7.6 Hz, $2 \mathrm{H}, \mathrm{Ar}-\mathrm{H}), 7.54(\mathrm{~d}, J=8.0 \mathrm{~Hz}, 2 \mathrm{H}, \mathrm{Ar}-\mathrm{H}) .{ }^{13} \mathrm{C}$ NMR $(100 \mathrm{MHz}$ DMSO- $\left.d_{6}, \delta, \mathrm{ppm}\right): 166.4,162.6,157.6,153.7,148.4,143.4$, 137.5, 133.4 (2C), 130.6, 129.3, 127.2, 125.6, 124.4 (2C), 122.4 120.6. MS (EI, $m / z \quad(\%)): 399[\mathrm{M}+\mathrm{H}]^{+}$. Anal. calcd. for $\mathrm{C}_{17} \mathrm{H}_{10} \mathrm{~N}_{4} \mathrm{O}_{4} \mathrm{~S}_{2}$ : C, 51.25; H, 2.53; N, 14.06. Found: C, 51.29; $\mathrm{H}$, $2.62 ; \mathrm{N}, 14.12 \%$.

2-Imino-5-(4-methoxybenzylidene)-3-(6-nitrobenzo[d] thiazol-2-yl)thiazolidin-4-one (6c): Color: Brown. Yield: $84 \% .{ }^{1} \mathrm{H}$ NMR (400 MHz, DMSO- $\left.d_{6}, \delta, \mathrm{ppm}\right): 12.98(\mathrm{~s}, 1 \mathrm{H}, \mathrm{NH}), 8.47(\mathrm{~s}$, $1 \mathrm{H}, \mathrm{Ar}-\mathrm{H}), 8.39$ (d, $J=6.8 \mathrm{~Hz}, 1 \mathrm{H}, \mathrm{Ar}-\mathrm{H}), 8.29(\mathrm{~d}, J=7.2 \mathrm{~Hz}, 1 \mathrm{H}$, Ar-H), 7.87 (d, $J=7.6 \mathrm{~Hz}, 2 \mathrm{H}, \mathrm{Ar}-\mathrm{H}), 7.83(\mathrm{~s}, 1 \mathrm{H}, \mathrm{CH}), 7.72(\mathrm{~d}, J=$ $7.2 \mathrm{~Hz}, 2 \mathrm{H}, \mathrm{Ar}-\mathrm{H}), 3.94\left(\mathrm{~s}, 3 \mathrm{H}, \mathrm{CH}_{3}\right) .{ }^{13} \mathrm{C}$ NMR $(100 \mathrm{MHz}$, DMSO$\left.d_{6}, \delta, \mathrm{ppm}\right): 165.3,160.6,156.5,152.4,144.3,142.4,139.3$, 132.9 (2C), 130.4, 128.6, 126.9, 126.0, 123.9 (2C), 122.4, 120.3, 60.1. MS (EI, $m / z \quad(\%)): 413[\mathrm{M}+\mathrm{H}]^{+}$. Anal. calcd. for $\mathrm{C}_{18} \mathrm{H}_{12} \mathrm{~N}_{4} \mathrm{O}_{4} \mathrm{~S}_{2}$ : C, 52.42; H, 2.93; N, 13.58. Found: C, 52.49; H, $3.00 ; \mathrm{N}, 13.67 \%$.

5-(4-(Benzyloxy)benzylidene)-2-imino-3-(6-nitrobenzo[d] thiazol-2-yl)thiazolidin-4-one (6d): Color: Brown. Yield: $91 \%$. ${ }^{1} \mathrm{H}$ NMR (400 MHz, $\left.\mathrm{CDCl}_{3}, \delta, \mathrm{ppm}\right): 12.42$ (s, $\left.1 \mathrm{H}, \mathrm{NH}\right), 8.61$ (s, $1 \mathrm{H}, \mathrm{Ar}-\mathrm{H}), 8.32(\mathrm{~d}, J=7.2 \mathrm{~Hz}, 1 \mathrm{H}, \mathrm{Ar}-\mathrm{H}), 8.10(\mathrm{~d}, J=7.2 \mathrm{~Hz}, 1 \mathrm{H}$, Ar-H), 7.99 (d, J = 7.2 Hz, 2H, Ar-H), 7.87-7.69 (m, 6H, Ar-H + $\mathrm{CH}), 7.63-7.58(\mathrm{~m}, 2 \mathrm{H}, \mathrm{Ar}-\mathrm{H}), 5.15\left(\mathrm{~s}, 2 \mathrm{H}, \mathrm{CH}_{2}\right) .{ }^{13} \mathrm{C}$ NMR $(75$ $\left.\mathrm{MHz}, \mathrm{CDCl}_{3}, \delta, \mathrm{ppm}\right): 168.7,163.0,155.4,145.4,141.6,139.2$, $138.3,136.4,135.3,134.2,133.8(2 \mathrm{C}), 132.6,131.8$ (2C), 131.2, 130.7, 127.4 (2C), 125.9, 125.2 (2C), 121.5, 71.1. MS (EI, $m / z$ (\%)): $489[\mathrm{M}+\mathrm{H}]^{+}$. Anal. calcd. for $\mathrm{C}_{24} \mathrm{H}_{16} \mathrm{~N}_{4} \mathrm{O}_{4} \mathrm{~S}_{2}$ : C, 59.00; $\mathrm{H}$, 3.30; N, 11.47. Found: C, 59.12; H, 3.34; N, $11.52 \%$.

2-Imino-5-(4-methylbenzylidene)-3-(6-nitrobenzo[d] thiazol2-yl)thiazolidin-4-one (6e): Color: Yellow. Yield: $88 \% .{ }^{1} \mathrm{H}$ NMR (400 MHz, CDCl $, \delta, \mathrm{ppm}): 12.33(\mathrm{~s}, 1 \mathrm{H}, \mathrm{NH}), 8.32(\mathrm{~s}, 1 \mathrm{H}, \mathrm{Ar}-\mathrm{H})$, 8.21 (d, J = 7.2 Hz, 1H, Ar-H), 8.01 (d, J= 7.6 Hz, 1H, Ar-H), 7.72 $(\mathrm{s}, 1 \mathrm{H}, \mathrm{CH}), 7.63(\mathrm{~d}, J=7.2 \mathrm{~Hz}, 2 \mathrm{H}, \mathrm{Ar}-\mathrm{H}), 7.56(\mathrm{~d}, J=7.2 \mathrm{~Hz}, 2 \mathrm{H}$, $\mathrm{Ar}-\mathrm{H}), 2.43$ (s, $\left.3 \mathrm{H}, \mathrm{CH}_{3}\right) .{ }^{13} \mathrm{C} \mathrm{NMR}\left(100 \mathrm{MHz}, \mathrm{CDCl}_{3}, \delta, \mathrm{ppm}\right)$ : 166.3, 161.8, 153.3, 149.6, 141.3, 139.2, 135.6(2C), 134.1 (2C), 133.2, 131.5, 128.6, 127.2, 126.2, 124.6, 123.4, 21.9. MS (EI, $m / z$ (\%)): $397[\mathrm{M}+\mathrm{H}]^{+}$. Anal. calcd. for $\mathrm{C}_{18} \mathrm{H}_{12} \mathrm{~N}_{4} \mathrm{O}_{3} \mathrm{~S}_{2}$ : C, 54.53; $\mathrm{H}$, 3.05; N, 14.13. Found: C, 54.61; H, 3.09; N, $14.21 \%$.

5-(4-(Dimethylamino)benzylidene)-2-imino-3-(6-nitrobenzo [d] thiazol-2-yl)thiazolidin-4-one (6f): Color: Yellow. Yield: 72\%. ${ }^{1} \mathrm{H} \mathrm{NMR}\left(400 \mathrm{MHz}, \mathrm{CDCl}_{3}, \delta, \mathrm{ppm}\right): 12.40(\mathrm{~s}, 1 \mathrm{H}, \mathrm{NH}), 8.34(\mathrm{~s}$, $1 \mathrm{H}, \mathrm{Ar}-\mathrm{H}), 8.19$ (d, J = 7.2 Hz, 1H, Ar-H), 8.01 (d, J = 7.2 Hz, $1 \mathrm{H}$, $\mathrm{Ar}-\mathrm{H}), 7.72(\mathrm{~s}, 1 \mathrm{H}, \mathrm{CH}), 7.69-7.63(\mathrm{~m}, 2 \mathrm{H}, \mathrm{Ar}-\mathrm{H}), 7.54(\mathrm{~d}, J=8.0$ $\mathrm{Hz}, 2 \mathrm{H}, \mathrm{Ar}-\mathrm{H}), 3.12\left(\mathrm{~s}, 6 \mathrm{H}, 2 \mathrm{CH}_{3}\right) .{ }^{13} \mathrm{C}$ NMR $\left(100 \mathrm{MHz}\right.$, DMSO- $d_{6}$, $\delta, \mathrm{ppm}): 168.7,163.2,156.4,149.4,144.5,143.4,138.6,136.2$, 134.0 (2C), 133.4, 130.4, 127.9, 126.8 (2C), 125.1, 123.4, 44.1 (2C). MS (EI, $m / z(\%)): 426[\mathrm{M}+\mathrm{H}]^{+}$. Anal. calcd. for $\mathrm{C}_{19} \mathrm{H}_{15} \mathrm{~N}_{5} \mathrm{O}_{3} \mathrm{~S}_{2}$ : C, 53.63; H, 3.55; N, 16.46. Found: C, 53.69; H, $3.62 ; \mathrm{N}, 16.51 \%$. 


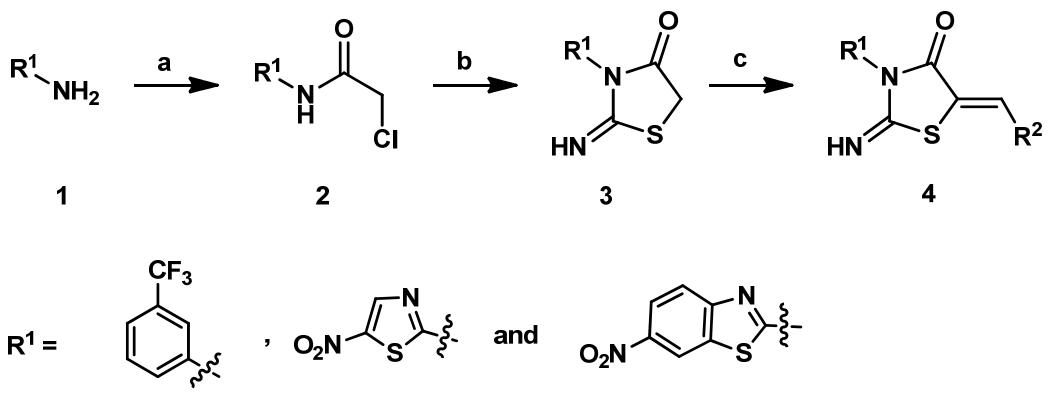

Reagents \& Conditions: a: Chloroacetyl chloride, Benzene, reflux, 6 h; b: KSCN, Acetone, reflux, $3 \mathrm{~h}$; $\mathrm{c}: \mathrm{R}^{2} \mathrm{CHO}, \mathrm{NaOAc}, \mathrm{Ac}_{2} \mathrm{O}, 100^{\circ} \mathrm{C}, 3 \mathrm{~h}$;

Figure 2. General synthetic procedure.

2-Imino-3-(6-nitrobenzo[d] thiazol-2-yl)-5-(3,4,5-trimethoxy benzylidene)thiazolidin-4-one (6g): Color: Light Yellow. Yield: 83\%. ${ }^{1} \mathrm{H}$ NMR (400 MHz, DMSO- $d_{6}, \delta, \mathrm{ppm}$ ): 13.03 (s, $1 \mathrm{H}, \mathrm{NH}$ ), $8.55(\mathrm{~s}, 1 \mathrm{H}, \mathrm{Ar}-\mathrm{H}), 8.44(\mathrm{~d}, J=7.2 \mathrm{~Hz}, 1 \mathrm{H}, \mathrm{Ar}-\mathrm{H}), 8.26(\mathrm{~d}, J=7.6$ $\mathrm{Hz}, 1 \mathrm{H}, \mathrm{Ar}-\mathrm{H}), 7.72(\mathrm{~s}, 1 \mathrm{H}, \mathrm{CH}), 7.54$ (s, 2H, Ar-H), 3.96 (s, 9H, $\left.3 \mathrm{CH}_{3}\right) .{ }^{13} \mathrm{C}$ NMR $\left(100 \mathrm{MHz}, \mathrm{DMSO}-d_{6}, \delta, \mathrm{ppm}\right): 168.4,162.3$, $154.8,154.2$ (2C), 146.2, 145.6, 138.7, 136.9, 135.6, 134.5, 133.2, 132.6, 131.3, 130.6, 126.2 (2C), 61.6, 61.2 (2C). MS (EI, $\mathrm{m} / z(\%)): 473[\mathrm{M}+\mathrm{H}]^{+}$. Anal. calcd. for $\mathrm{C}_{20} \mathrm{H}_{16} \mathrm{~N}_{4} \mathrm{O}_{6} \mathrm{~S}_{2}$ : C, 50.84; H, 3.41; N, 11.86. Found: C, 50.92; H, 3.45; N, 11.92\%.

5-(2-Fluorobenzylidene)-2-imino-3-(6-nitrobenzo[d]thiazol2-yl)thiazolidin-4-one (6h): Color: Brown. Yield: 79\%. ${ }^{1 \mathrm{H}} \mathrm{NMR}$ (400 MHz, DMSO- $\left.d_{6}, \delta, p p m\right): 10.43(\mathrm{~s}, 1 \mathrm{H}, \mathrm{NH}), 8.44(\mathrm{~s}, 1 \mathrm{H}, \mathrm{Ar}-$ $\mathrm{H}), 8.31(\mathrm{~d}, J=7.2 \mathrm{~Hz}, 1 \mathrm{H}, \mathrm{Ar}-\mathrm{H}), 8.22(\mathrm{~d}, J=6.8 \mathrm{~Hz}, 1 \mathrm{H}, \mathrm{Ar}-\mathrm{H})$, $7.89(\mathrm{t}, J=7.2 \mathrm{~Hz}, 1 \mathrm{H}, \mathrm{Ar}-\mathrm{H}), 7.81-7.69(\mathrm{~m}, 3 \mathrm{H}, \mathrm{Ar}-\mathrm{H}), 7.65$ (d, $J=$ $7.6 \mathrm{~Hz}, 1 \mathrm{H}, \mathrm{Ar}-\mathrm{H}) .{ }^{13} \mathrm{C}$ NMR (100 MHz, DMSO-d $\left.6, \delta, \mathrm{ppm}\right): 166.5$, $160.6,153.3,147.4,137.4,136.4,134.9,132.5,131.3,129.6$, 127.4, 126.7, 124.6, 123.3, 122.4, 121.3, 120.6. MS (EI, $\mathrm{m} / \mathrm{z}$ (\%)): $401[\mathrm{M}+\mathrm{H}]^{+}$. Anal calcd. for $\mathrm{C}_{17} \mathrm{H}_{9} \mathrm{FN}_{4} \mathrm{O}_{3} \mathrm{~S}_{2}$ : C, 50.99; $\mathrm{H}$, 2.27; N, 13.99. Found: C, 51.10; H, 2.29; N, 14.06\%.

5-(4-Chlorobenzylidene)-2-imino-3-(6-nitrobenzo[d]thiazol2-yl)thiazolidin-4-one (6i): Color: Light Yellow. Yield: $72 \% .{ }^{1} \mathrm{H}$ NMR (400 MHz, DMSO- $\left.d_{6}\right): 12.79(\mathrm{~s}, 1 \mathrm{H}, \mathrm{NH}), 8.24(\mathrm{~d}, J=7.2 \mathrm{~Hz}$, $1 \mathrm{H}, \mathrm{Ar}-\mathrm{H}), 8.12(\mathrm{~d}, J=6.8 \mathrm{~Hz}, 1 \mathrm{H}, \mathrm{Ar}-\mathrm{H}), 7.99(\mathrm{~s}, 1 \mathrm{H}, \mathrm{Ar}-\mathrm{H}), 7.81$ (d, $J=7.6 \mathrm{~Hz}, 2 \mathrm{H}, \mathrm{Ar}-\mathrm{H}), 7.79$ (s, $1 \mathrm{H}, \mathrm{CH}), 7.77$ (d, $J=8.0 \mathrm{~Hz}, 2 \mathrm{H}$, Ar-H). ${ }^{13} \mathrm{C}$ NMR $\left(100 \mathrm{MHz}, \mathrm{DMSO}-d_{6}, \delta, \mathrm{ppm}\right): 165.3,158.8$, 154.4, 146.2, 139.3, 136.9, 135.1, 133.4, 132.8 (2C), 129.1 (2C), $127.4,125.1,123.7,121.4,120.0$. MS (EI, $m / z(\%)): 417[\mathrm{M}+\mathrm{H}]^{+}$. Anal. calcd. for $\mathrm{C}_{17} \mathrm{H}_{9} \mathrm{ClN}_{4} \mathrm{O}_{3} \mathrm{~S}_{2}$ : C, 48.98; H, 2.18; N, 13.44 Found C, 49.03; H, 2.23; N, 13.53\%.

2-Imino-3-(6-nitrobenzo[d]thiazol-2-yl)-5-(3-nitrobenzylide ne)thiazolidin-4-one (6j): Color: Yellow. Yield: $84 \% .{ }^{1} \mathrm{H}$ NMR (400 MHz, DMSO- $d_{6}, \delta, \mathrm{ppm}$ ): 12.75 (s, 1H, NH), 8.31 (s, 1H, Ar$\mathrm{H}), 8.16(\mathrm{~d}, J=7.2 \mathrm{~Hz}, 1 \mathrm{H}, \mathrm{Ar}-\mathrm{H}), 8.11(\mathrm{~s}, 1 \mathrm{H}, \mathrm{Ar}-\mathrm{H}), 7.92(\mathrm{~d}, J=$ $7.2 \mathrm{~Hz}, 1 \mathrm{H}, \mathrm{Ar}-\mathrm{H}), 7.82(\mathrm{~s}, 1 \mathrm{H}, \mathrm{CH}), 7.72-7.62(\mathrm{~m}, 3 \mathrm{H}, \mathrm{Ar}-\mathrm{H}) .{ }^{13} \mathrm{C}$ NMR (100 MHz, DMSO- $\left.d_{6}, \delta, \mathrm{ppm}\right): 167.1,161.4,156.2,147.2$, $142.4,139.4,138.1,136.2,134.5,133.0,132.4,128.0,126.0$, 124.1, 123.6, 121.6, 120.4. MS (EI, $m / z(\%)): 428[\mathrm{M}+\mathrm{H}]^{+}$. Anal. calcd. for $\mathrm{C}_{17} \mathrm{H}_{9} \mathrm{~N}_{5} \mathrm{O}_{5} \mathrm{~S}_{2}$ : C, 47.77; $\mathrm{H}, 2.12 ; \mathrm{N}, 16.39$. Found: C, 47.81; H, 2.16; N, 16.44\%.

2-Imino-3-(6-nitrobenzo[d] thiazol-2-yl)-5-((5-nitrofuran-2yl)methylene)thiazolidin-4-one (6k): Color: Brown. Yield: 70\%. ${ }_{1}^{1} \mathrm{H} \mathrm{NMR}\left(400 \mathrm{MHz}, \mathrm{CDCl}_{3}, \delta, \mathrm{ppm}\right): 12.33(\mathrm{~s}, 1 \mathrm{H}, \mathrm{NH}), 8.31$ (d, $J=$ $7.2 \mathrm{~Hz}, 1 \mathrm{H}, \mathrm{Ar}-\mathrm{H}), 8.21(\mathrm{~d}, J=7.6 \mathrm{~Hz}, 1 \mathrm{H}, \mathrm{Ar}-\mathrm{H}), 8.08(\mathrm{~d}, J=7.2$ $\mathrm{Hz}, 1 \mathrm{H}, \mathrm{Ar}-\mathrm{H}), 7.99$ (s, $1 \mathrm{H}, \mathrm{CH}), 7.91$ (d, $J=7.6 \mathrm{~Hz}, 1 \mathrm{H}, \mathrm{Ar}-\mathrm{H})$, 7.80 (s, $1 \mathrm{H}, \mathrm{Ar}-\mathrm{H}) .{ }^{13} \mathrm{C}$ NMR $\left(100 \mathrm{MHz}, \mathrm{CDCl}_{3}, \delta, \mathrm{ppm}\right): 170.2$, $161.1,156.2,152.4,144.6,140.4,138.3,136.5,134.8,133.3$, 129.4, 126.4, 124.6, 123.6, 121.5. MS (EI, $m / z(\%)): 418[\mathrm{M}+\mathrm{H}]^{+}$. Anal. calcd. for $\mathrm{C}_{15} \mathrm{H}_{7} \mathrm{~N}_{5} \mathrm{O}_{6} \mathrm{~S}_{2}$ : C, 43.17; H, 1.69; N, 16.78. Found: C, $43.22 ; \mathrm{H}, 1.72 ; \mathrm{N}, 16.82 \%$.
2-Imino-3-(6-nitrobenzo[d]thiazol-2-yl)-5-((5-nitrothiophen2-yl)methylene)thiazolidin-4-one (61): Color: Yellow. Yield: $72 \%$. ${ }^{1} \mathrm{H}$ NMR (400 MHz, $\left.\mathrm{CDCl}_{3}, \delta, \mathrm{ppm}\right): 12.44(\mathrm{~s}, 1 \mathrm{H}, \mathrm{NH}), 8.29$ (d, $J=$ $7.2 \mathrm{~Hz}, 1 \mathrm{H}, \mathrm{Ar}-\mathrm{H}), 8.17(\mathrm{~d}, J=7.6 \mathrm{~Hz}, 1 \mathrm{H}, \mathrm{Ar}-\mathrm{H}), 8.01(\mathrm{~d}, J=7.2$ $\mathrm{Hz}, 1 \mathrm{H}, \mathrm{Ar}-\mathrm{H}) 7.99$ (s, 1H, CH), 7.89 (d, J= $7.6 \mathrm{~Hz}, 1 \mathrm{H}, \mathrm{Ar}-\mathrm{H}), 7.72$ (s, 1H, Ar-H). ${ }^{13} \mathrm{C}$ NMR $\left(100 \mathrm{MHz}, \mathrm{CDCl}_{3}, \delta, \mathrm{ppm}\right): 171.3,160.4$, 156.6, 153.0, 145.3, 142.0, 139.1, 137.2, 134.7, 133.3, 128.9, 127.1, 125.2, 124.2, 121.9. MS (EI, $m / z(\%)): 434[\mathrm{M}+\mathrm{H}]^{+}$. Anal calcd. for $\mathrm{C}_{15} \mathrm{H}_{7} \mathrm{~N}_{5} \mathrm{O}_{5} \mathrm{~S}_{3}: \mathrm{C}, 41.57 ; \mathrm{H}, 1.63$; N, 16.16. Found: C, 41.62; $\mathrm{H}, 1.69 ; \mathrm{N}, 16.24 \%$.

\subsection{In vitro MTB screening}

Two-fold serial dilutions of each test compound/drug were prepared and incorporated into Middle-Brook 7H11 agar medium with oleic acid, albumin, dextrose, and catalase (OADC) growth supplement to get final concentrations of 50 $25,12.5,6.25,3.13,1.56$, and $0.78 \mu \mathrm{g} / \mathrm{mL}$. Inoculum of $M$. tuberculosis H37Rv ATCC 27294 was prepared from fresh Middlebrook 7H11 agar slants with OADC (Difco) growth supplement adjusted to $1 \mathrm{mg} / \mathrm{mL}$ (wet weight) in Tween 80 $(0.05 \%)$ saline diluted to $10^{-2}$ to give a concentration of $\sim 10^{7}$ $\mathrm{cfu} / \mathrm{mL}$. Five microliters of this bacterial suspension was spotted onto 7H11 agar tubes containing different concentrations of the drug as discussed above [10]. The tubes were incubated at $37^{\circ} \mathrm{C}$, and final readings (as MIC in $\mu \mathrm{g} / \mathrm{mL}$ ) were determined after 28 days. The MIC is defined as the minimum concentration of compound required to give complete inhibition of bacterial growth. This method is similar to that recommended by the National Committee for Clinical Laboratory Standards for the determination of MIC in triplicate.

Susceptibility testing in the presence of the efflux inhibitors verapamil was carried out by adding the respective inhibitor at sub inhibitory concentrations $(0.25 \times$ MIC) to the MTB cultures in the assay. The MICs of verapamil $>200 \mu \mathrm{g}$ (taken as $200 \mu \mathrm{g}$ ).

\subsection{In vitro cytotoxicity screening}

Some compounds were further examined for toxicity in a RAW 264.7 cell line at the concentration of $50 \mu \mathrm{M}$. After $72 \mathrm{~h}$ of exposure, viability was assessed on the basis of cellular conversion of MTT into a formazan product using the Promega Cell Titer 96 non-radioactive cell proliferation assay.

\section{Results and discussion}

\subsection{Chemistry}

The target molecules were synthesised by following the three step synthetic protocol (Figure 2). 
Table 1. Biological activities of synthesized compounds.

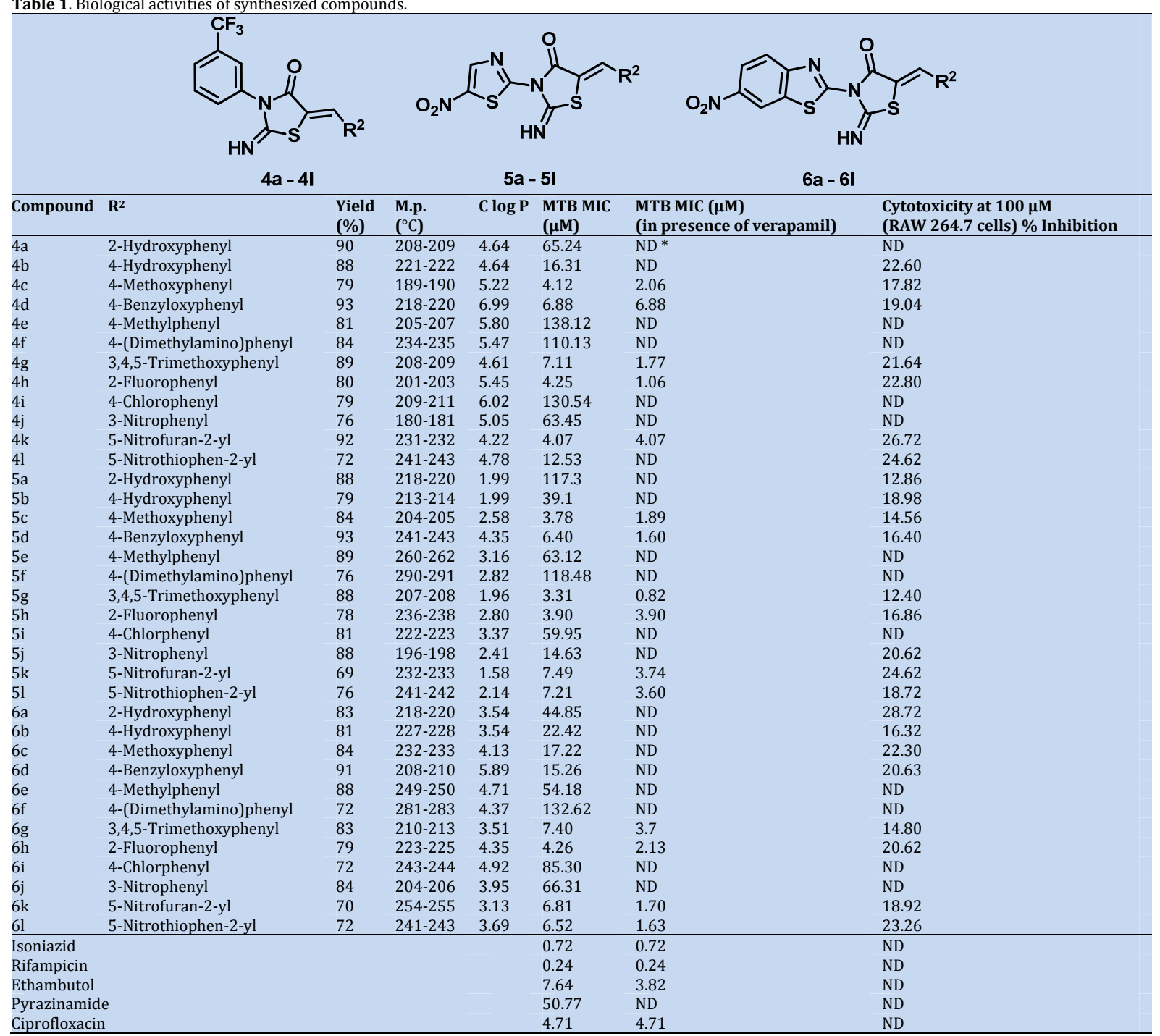

*ND indicates not determined.

In the first step we treated the amines (1) like 3trifluromethyaniline, 2-amino-5-nitrothiazole and 2-amino-6nitrobenzothiazole with chloro acetylchloride without using any base under thermal conditions to get corresponding chloroacetamide derivatives (2).

Refluxing of chloroacetamide derivatives (2) and potassium thiocyanate in acetone for 3 hours yield the correspondding cyclised 3-substituted-2-iminothiazolidine-4-ones (3). In final step we used Knoevenagal condensation [11] of the compound 3 with various substituted aldehydes using $\mathrm{NaOAc} /$ acetic acid at $100{ }^{\circ} \mathrm{C}$, to produce title compounds (4a-l, 5a-l and 6a-1). These reactions were also successfully carried out using piperidine/ethanol at $90{ }^{\circ} \mathrm{C}$, but former reaction conditions favoured the easy purification, due to the lower solubility's of formed products in acetic acid. Direct filtration of reaction mixture and washing of residue with excess water, cold ethanol, ethers and hexanes produced the final compounds with good purity and in excellent yields (Table 1).

\subsection{Anti-TB activity and structure-activity relationship}

The compounds were screened for their in vitro antimycobacterial activity against $M$. tuberculosis $\mathrm{H} 37 \mathrm{Rv}$ by microplate alamar blue assay method [12] for the determination of MIC in duplicate. The minimum inhibitory concentration is defined as the minimum concentration of compound required togive complete inhibition of bacterial growth. MICs of the synthesized compounds along with the standard drugs for comparison are reported (Table 1). The compounds showed MIC's ranging from 3.31-138.12 $\mu \mathrm{M}$; and fifteen compounds showed promising activity with MIC of less than $10 \mu \mathrm{M}$. When compared to original lead compound SID: 24823007; all the compounds were found to be less active. When compared to standard first line antitubercular drug ethambutol (MIC of $7.64 \mu \mathrm{M}$ ), fifteen compounds were found to be more active and when compared to pyrazinamide (MIC of $50.77 \mu \mathrm{M})$, twenty-five compounds were more active. All the molecules were found is less active than isoniazid (MIC of 0.72 $\mu \mathrm{M}$ ) and rifampicin (MIC of $0.24 \mu \mathrm{M}$ ) but seven compounds were more active than DNA gyrase inhibitor ciprofloxacin (MIC of $4.71 \mu \mathrm{M})$. Among the compounds, 2-imino-3-(5-nitrothiazol2-yl)-5-(3, 4, 5-trimethoxybenzylidene)thiazolidin-4-one (5g) was found to be the most active compound in vitro with MICs of $3.31 \mu \mathrm{M}$. To study the SAR we prepared the compounds with variations in $\mathrm{N}-3$ and $\mathrm{C}-5$ positions. In $\mathrm{N}-3$ position we have tried with 3-trifluoromethyphenyl (4a-1), 5-nitrothiazol-2-yl 
(5a-1) and 6-nitrobenzothiazol-2-yl (6a-1) groups. The order of activity with respect to $\mathrm{N}-3$ position were; 6-nitrobenzothiazol2-yl > 3-trifluoromethyphenyl > 5-nitrothiazol-2-yl group. In the $\mathrm{C}-5$ position we have prepared molecules with phenyl ring with both electron donating and electron with drawing groups and also with few heterocycles. In the case of phenyl ring at position C-5; 4-hydroxyl substituent $(\mathbf{4 b}, \mathbf{5 b}$, and $\mathbf{6 b})$ were found to be two to four times more potent than 2-hydroxyl substituent (4a, 5a, and 6a). Replacement of 4-hydroxyl group with 4-methoxyl (4c, 5c, and $\mathbf{6 c}$ ) and 4-benzyloxy group (4d, 5d, and 6d) increases the activity; whereas methyl group (4e, $\mathbf{5 e}$ and $\mathbf{6 e}$ ) and dimethylamino group (4f, $5 \mathbf{f}$, and $\mathbf{6 f}$ ) decreases the activity drastically. Tri substitution with 3,4,5-trimethoxyl group $(\mathbf{4 g}, \mathbf{5 g}$, and $\mathbf{6 g}$ ) showed good potency with MIC of $<8$ $\mu \mathrm{M}$. In the case of electron withdrawing groups; substitution with 2-fluoro group ( $\mathbf{4 h}, \mathbf{5 h}$, and $\mathbf{6 h}$ ) showed good activity with MIC of $<5 \mu \mathrm{M}$; whereas substituents like 4-chloro group (4i, $\mathbf{5 i}$ and $\mathbf{6 i}$ ) and 3-nitro groups $(\mathbf{4 j}, \mathbf{5 j}$ and $\mathbf{6 j}$ ) were detrimental for activity. With respect to heterocyclic substituents; we prepared with 5-nitrofuran-2-yl and 5-nitrothiophen-2-yl groups and both of them provides good activity [13]. We have also calculated $\operatorname{ClogP}$ with Chemdraw 8.0 for all the compounds to see the relationship between lipophilicity and antitubercular activity; but it was not correlating (Table 1).

When compared to lead compound SID: 24823007, all the synthesized compounds showed less activity. It could be due to involvement of wide array of efflux mechanisms mediated by several ABC (ATP-binding cassette) transporters and major facilitator superfamily (MFS) proteins, or antibiotic-modifying and -degrading enzymes, to name a few possibilities [14]. Multiple drugs like verapamil, reserpine, phenothiazines such as thioridazine, and piperine have been shown to inhibit bacterial efflux pumps in vitro [15]. In general, the mechanisms by which these agents act are poorly understood. Several models have been proposed [16], such as: (1) direct binding and inhibition of pump assembly or function; (2) disruption of the transmembrane gradients utilized by secondary transporters; (3) inhibitor binding to the antimicrobial compound; (4) competition for efflux. We have tested some selected compounds [MIC of $<10 \mu \mathrm{M}$ ], in presence of reported efflux pump inhibitor verapamil; and most of the cases MIC decreased 2 to 4 fold when compared to absence of efflux pump. Most active compound $\mathbf{5 g}$ showed MIC of $0.82 \mu \mathrm{M}$

\subsection{Cytotoxicity study}

Compounds which showed MIC of less than $50 \mu \mathrm{M}$ were further examined for cytotoxicity in a RAW 264.7 cell line (mouse leukaemic monocyte macrophage) at single concentration of $100 \mu \mathrm{M}$. We have selected this macrophage cell line to test the toxicity because generally MTB used to reside inside the macrophages and the new molecules should not possess any toxicity against macrophages. After $72 \mathrm{~h}$ of exposure, viability was assessed on the basis of cellular conversion of MTT into a formazan product using the Promega Cell Titer 96 non-radioactive cell proliferation assay. Most of the tested compounds were not cytotoxic to RAW 264.7 cells and their percentage growth inhibitions were reported in Table 1 . The most active anti-TB compound $\mathbf{5 g}$ has shown toxicity of $12.4 \%$ at $100 \mu \mathrm{M}$ with selectivity index of $>30$ for MTB.

\section{Conclusion}

In this study we have designed, synthesized and study the SAR of various inhibitors of MTB based on the lead compound SID: 24823007 reported by TAACF. Among the compounds, 2imino-3-(5-nitrothiazol-2-yl)-5-(3,4,5-trimethoxybenzylidene) thiazolidin-4-one (19) was found to be the most active compound in vitro with MICs of $3.31 \mu \mathrm{M}$ against log-phase culture of MTB and also non-toxic up to $100 \mu \mathrm{M}$, but compound $\mathbf{5 g}$ is less potent than lead compound SID: 24823007.
Compound 5 g showed MIC of $0.82 \mu \mathrm{M}$ in presence of efflux pump inhibitor. Further structural optimization required to get the compounds with better potency than the lead compound and also to explore the possible mechanism of action against various MTB essential enzymes. In addition, efflux could be the rate-limiting step in the discovery of novel anti-TB compounds, as has already been recognized in the discovery of drugs for Gram-negative bacterial infections. The discovery of new pumps with multiple specificities in MTB and the impact these pumps have on antitubercular therapy by conferring resistance to many of the new molecules discovered necessitate the study of efflux mechanisms as an important therapeutic target.

\section{Acknowledgements}

The authors are thankful to Department of Science \& Technology (SR/S1/OC-70/2010), New Delhi, India for their financial assistances. Ganesh Samala is thankful to Council of Scientific \& Industrial Research for providing fellowship.

\section{References}

[1]. World Health Organization, 2011/2012 Tuberculosis Global Facts, Geneva, Switzerland, 2011.

[2]. Berry, M.; Kon, O. M. Eur. Respir. Rev. 2009, 18, 195-197.

[3]. Koul, A.; Arnoult, E.; Lounis, N.; Guillemont, J.; Andries, K. Nature 2011, 469, 483-490.

[4]. Choi, J. Y.; Plummer, M. S.; Starr, J.; Desbonnet, C. R.; Soutter, H.; Chang, J.; Miller, J. R.; Dillman, K.; Miller, A. A.; Roush, W. R. J. Med. Chem. 2012, 55, 852-870.

[5]. Payne, D. J.; Gwynn, M. N.; Holmes, D. J.; Pompliano, D. L. Nat. Rev. Drug. Discov. 2007, 6, 29-40.

[6]. Norbert, H.; Kurt, M.; Richard, W.; available online at http://merian.pch.univie.ac.at/pch/pub/nh7.pdf.

[7]. Reynolds, R. C.; Ananthan, S.; Faaleolea, E.; Hobrath, J. V.; Kwong, C. D.; Maddox, C.; Rasmussen, L.; Sosa, M. I.; Thammasuvimol, E.; White, E. L.; Zhang, W.; Secrist, J. A. Tuberculosis 2012, 92, 72-83.

[8]. Ananthan, S.; Faaleolea, E. R.; Goldman, R. C.; Hobrath, J. V.; Kwong, C. D.; Laughon, B. E.; Maddry, J. A.; Mehta, A.; Rasmussen, L.; Reynolds, R. C.; Secrist, J. A. 3rd.; Shindo, N.; Showe, D. N.; Sosa, M. I.; Suling, W. J.; White, E. L. Tuberculosis 2009, 89, 334-353.

[9]. Maddry, J. A.; Ananthan, S.; Goldman, R. C.; Hobrath, J. V.; Kwong, C. D. Maddox, C.; Rasmussen, L.; Reynolds, R. C.; Secrist, J. A.; Sosa, M. I.; White, E. L.; Zhang, W. Tuberculosis 2009, 89, 354-363.

[10]. Sriram, D.; Yogeeswari, P.; Senthilkumar, P.; Sangaraju, D.; Nelli, R.; Banerjee, D.; Bhat, P.; Manjashetty, T. H. Chem. Biol. Drug. Des. 2010, 75, 381-391.

[11]. Kulkarni, A. A.; Wankhede, S. B.; Dhawale, N. D.; Yadav, P. B.; Deore, V. V.; Gonjari, I. D. Arabian. J. Chem. In press, DOI: 10.1016/j.arabjc.2012.07.020

[12]. Franzblau, S. G.; Witzig, R. S.; McLaughlin, J. C.; Torres, P.; Madico, G.; Hernandez, A.; Degnan, M. T.; Cook, M. B.; Quenzer, V. K.; Ferguson, R. M.; Gilman, R. H. J. Clin. Microbiol. 1998, 36, 362-366.

[13]. Weir-Torn. J.; Tsu, A. H.; Wen, H. L.; Yu, S. C. US 2012/0225880 A1.

[14]. De Rossi, E.; Ainsa, J. A.; Riccardi, G. FEMS. Microbiol. Rev. 2006, 30, 36-52.

[15]. Rodrigues, L.; Ainsa, J. A.; Amaral, L.; Viveiros, M. Recent. Pat. AntiInfect Drug. Discovery. 2011, 6, 118-127.

[16]. Pages, J. M.; Amaral, L. Biochim. Biophys. Acta. 2009, 1794, 826-833. 